\title{
СРАВНИТЕЛЬНАЯ ОЦЕНКА СТРУКТУРНО-АГРЕГАТНОГО СОСТАВА ТЕМНО-СЕРЫХ ЛЕСНЫХ ПОЧВ ЛЕСОСТЕПНОЙ ЗОНЫ ЗАУРАЛЬЯ
}

\author{
D.V. Eremina, N.A. Gruzdeva, D.I. Eremin
}

\section{COMPARATIVE ASSESSMENT OF THE STRUCTURAL AND AGGREGATE COMPOSITION OF DARK GRAY FOREST SOILS OF THE FOREST-STEPPE ZONE OF THE TRANS-URALS}

Еремина Д.В. - канд. с.-х. наук, доц. каф. математики и информатики Государственного аграрного университета Северного Зауралья, г. Тюмень.

E-mail: diana-eremina@mail.ru

Груздева Н.A. - вед. агрохимик Государственной станции агрохимической службы «Тюменская», г. Тюмень. E-mail: g.nessi@mail.ru

Еремин Д.И. - д-р биол. наук, проф. каф. почвоведения и агрохимии Государственного аграрного университета Северного Зауралья, г. Тюмень. E-mail: soil-tyumen@yandex.ru

Вовлечение почв в сельскохозяйственный оборот приводит к существенному изменению естественного почвообразовательного проиесса. Причиной этого является изменение характера поступления растительных остатков в почву, высокая аэрация, минеральные удобрения и механическое воздействие сельскохозяйственных орудий. В результате почвы начинают приобретать признаки, свойственные агроземам. В статье приводятся данные по изучению структурного состояния пахотных темно-серых лесных почв лесостепной зоны Зауралья. Исследования проводились на стационаре агрохимической станции «Тюменская», расположенном возле д. Успенка Тюменского района. В качестве эталона для сравнения был выбран участок иелинной темно-серой лесной почвы, расположенный в 200 метрах от пашни. Цель исследований изучение влияния антропогенного фактора на структурообразование темно-серых лесных почв. Изучали агрегатны й состав путем сухого и мокрого рассеивания почвенных образцов в колонке сит. Установлено, что структурная организация челинных темно-серых лесных почв Северного Зауралья оценивается как отличная, а водопрочность агрегатов - как хо-
Eremina D.V. - Cand. Agr. Sci., Assoc. Prof., Chair of Mathematics and Information Science, Northern Trans-Urals State Agrarian University, Tyumen.

E-mail: diana-eremina@mail.ru

Gruzdeva N.A. - Leading Agrochemist, State Agrochemical Service Station "Tyumenskaya", Tyumen. E-mail: g.nessi@mail.ru

Eremin D.I. - Dr. Biol. Sci., Prof., Chair of Soil Science and Agrochemistry, Northern Trans-Urals State Agrarian University, Tyumen.

E-mail: soil-tyumen@yandex.ru

рошая. Содержание агрономически иенных фрракций (0,25-10,0 мм) в гумусовом слое достигает $70 \%$, а коэфффициент структурности - 2,6 ед. Многолетнее использование темносерых лесных почв в пашне незначительно ухудшило структурное состояние за счет формирования гльІбистой структуры (>10 мм) в слое 0-60 см. Содержание агрономически ценных агрегатов в пахотном слое уменьшилось до $65 \%$, коэфффициент структурности снизился до 1,9 ед. Водоустойчивость темносерой лесной почвы в результате ее длительного сельскохозяйственного использования в пашне уменьшилась. Содержание мелкозема $(<0,25$ мм) в пахотном слое при мокром просеивании достигает $43 \%$, что существенно выше значений целинного участка. Глубже 20 см отклонений водопрочности почвенных агрегатов, вызванных антропогенным воздействием, обнаружено не было.

Ключевые слова: агрофизические свойства, структурообразование, агрономически ценная структура, средневзвешенный диаметр агрегатов, коэфффициент структурности, водопрочность, пахотный горизонт, пашня, антропогенный фактор, вспашка. 
The involvement of soils in agricultural turnover leads to a significant change in the natural soil formation process. The reason for this is a change in the nature of the receipt of plant residues in the soil, high aeration, mineral fertilizers and mechanical effects of agricultural tools. In the result, the soil begins to acquire the characteristics peculiar to agroseme. The article presents data on the study of the structural state of arable dark gray forest soils of the forest-steppe zone of the TRANS-Urals. The research was carried out at the hospital of the agrochemical station "Tyumenskaya", located near the village of Uspenka, Tyumen region. As a reference for comparison, a plot of virgin dark gray forest soil, located 200 meters from the arable land, was chosen. The aim of the research was to study the influence of anthropogenic factors on the structure formation of dark gray forest soils. The aggregate composition was studied by dry and wet dispersion of soil samples in a sieve column. It is established that the structural organization of virgin dark gray forest soils of the Northern TRANS-Urals is estimated as excellent, and the water quality of aggregates-as good. The content of agronomically valuable fractions $(0.25-10.0 \mathrm{~mm})$ in the humus layer reaches $70 \%$, and the structural coefficient2.6 units. the long-Term use of dark gray forest soils in arable land slightly worsened the structural condition due to the formation of a blocky structure $(>10 \mathrm{~mm})$ in the layer $0-60 \mathrm{~cm}$. the Content of agronomically valuable aggregates in the arable layer decreased to $65 \%$, the structural coefficient decreased to 1.9 units. The water resistance of dark gray forest soil has decreased as a result of its long-term agricultural use in arable land. The content of fine earth $(<0.25 \mathrm{~mm})$ in the arable layer during wet sieving reaches $43 \%$, which is significantly higher than the values of the virgin land. Deeper than $20 \mathrm{~cm}$ deviations of water quality of soil aggregates caused by anthropogenic impact were not found.

Keywords: agrophysical properties; structure formation; agronomically valuable structure; weighted average diameter of aggregates; structural coefficient; water depth; arable horizon; arable land; anthropogenic factor; plowing.

Введение. Подтип темно-серых лесных почв лесостепной зоны Зауралья характеризуется высоким уровнем эффективного и потенциаль- ного плодородия и не уступает по нему черноземным почвам Западной Сибири. Данный подтип преимущественно распространен в лесостепи и обычно граничит на возвышенностях с выщелоченными и оподзоленными черноземами, а в понижениях - с луговыми и луговочерноземными почвами. На юге Тюменской области наиболее распространены осолоделые почвы тяжелого гранулометрического состава, что делает их менее привлекательными с агрономической точки зрения. По данным Л.Н. Каретина, на их долю приходится 30 \% от всех серых лесных почв нашего региона [1].

Сельскохозяйственное освоение темносерых лесных почв началось еще в первой половине XIX века [2]. Распашка велась практически одновременно с черноземами, и до настоящего времени этот подтип серых лесных почв активно используется в пашне. Однако, как показала практика и агрохимический мониторинг, пахотные темно-серые лесные почвы постепенно теряют свое плодородие и темпы его снижения явно быстрее, чем у черноземов [3-5].

Благодаря достижениям науки, появились новые сорта и технологии возделывания сельскохозяйственных культур, способные вывести агропромышленный комплекс Сибири на новый технологический уровень [6-9]. Единственный ограничивающий фрактор - это дефицит плодородных почв. В последние десятилетия многократно возросла нагрузка на уже существующий пахотный фонд и распахиваются новые территории. В первую очередь распахивают серые лесные почвы. Поэтому необходимы знания об агрогенном влиянии на основополагающие показатели плодородия этих почв, в том числе на структурно-агрегатный состав.

Цель исследований. Изучение структурообразования пахотных темно-серых лесных почв лесостепной зоны Зауралья.

Объекты и методы исследований. Исследования по изучению структурно-агрегатного состава и водоустойчивости темно-серых лесных почв проводили на стационаре агрохимической станции «Тюменская», который расположен вблизи д. Успенка Тюменского района. Территория относится к северной лесостепи, координаты 57005'30" с.ш.; 65॰03'00" в.д. Почва темно-серая лесная среднесуглинистая. Целинный участок непосредственно примыкает к полю 
- находится в 200 м от места отбора почвенных образцов и представляет собой сильно изреженный березовый лес с хорошо развитым разнотравно-бобово-злаковым травяным покровом.

Формула почвенного профиля целинной темно-серой лесной почвы имеет следующий вид:

$\mathrm{A} 0(5 \mathrm{~cm})-\mathrm{A} 1(25 \mathrm{~cm})-\mathrm{B} 1(35 \mathrm{~cm})-\mathrm{B} 2(55 \mathrm{~cm})$ - Вк(50 см)-C.

За годы исследований на стационаре было внесено 230 т/га органических удобрений в виде торфо-навозного компоста и 557 кг д.в./га минерального азота. Было запахано 53 т/га пожнивно-корневых остатков, солома вывозилась с полей.

Севооборот за период с 1994 по 2019 г. был зернотравяно-пропашным. В качестве многолетних трав использовали злаково-бобовую смесь (клевер, тимофреевка). Система основной обработки почвы - отвальная, разноглубинная.

Почвенные образцы отбирали после уборки сельскохозяйственных культур, непосредственно перед вспашкой. На целинном участке отбор образцов проводили сопряженно с пашней. Пробы отбирали послойно с интервалом $10 \mathrm{~cm}$ на глубину до 70 см в 6-кратной повторности. Определение структурно-агрегатного состава проводили в лаборатории кафредры почвоведения и агрохимии ГАУ Северного Зауралья.

Структуру почвы определяли методом сухого просеивания через колонку сит с разным диаметром отверстий. После получения данных рассчитывали коэфффициент структурности по формуле

$$
K_{c m p}=\frac{\sum(10-0,25 M M)}{\sum(>10 M M+<0,25 M M} .
$$

Агрегатный состав изучали путем мокрого просеивания на приборе Бакшеева с последующим пересчетом суммы агрегатов с размерами более 0,25 мм.

Средневзвешенный диаметр (СВД) агрегатов (для сухого и мокрого просеивания) необходим для анализа структурного состояния, так как чем выше значения, тем крупнее агрегаты (значения менее 1 мм указывают на распыленность почвы). СВД (мм) рассчитывали по формуле

$$
C В Д=\frac{d_{1} \cdot p_{1}+d_{2} \cdot p_{2}+\ldots+d_{n} \cdot p_{n}}{100}
$$

где, $d_{1}, d_{2}, d_{n}-$ средний диаметр фрракций, мм; $p_{1}, p_{2}, p_{n}$ - содержание данной фракции, \%.

Расчеты ошибки опыта и достоверность полученных результатов (НСР) проводили по Доспехову. Указать, какой или какие показатели рассчитывали.

Результаты исследований и их обсуждение. Сухой рассев в колонке сит показал, что содержание агрономически ценных фрракций (АЦФ) в слое 0-20 см целинной темно-серой лесной почвы составляет $72 \%$, что соответствует отличному структурному состоянию (рис.). На долю глыбистых агрегатов (>10 мм) приходилось $6,2-8,7 \%$, а на мелкозем - $19-23 \%$.

В составе АЦФ доминирует фрракция 3-5 мм - на ее долю приходится 16,8-20,3 \%. Прослеживается тенденция укрупнения агрегатов в ходе естественного структурообразования. На долю структурных отдельностей с размерами 3,010,0 мм приходится около 50 \% содержания агрономически ценных агрегатов. С глубиной структура укрупняется - доля почвенных глыб (>10 мм) возрастает до 25,6 \%, а содержание пылеватой фракции (<0,25 мм) снижается до минимума - 0,3-1,9\%. Причиной этого является процесс иллювиирования, в результате которого часть илистого материала мигрировала вниз по профилю и активно включилась в формирование крупной структуры.

Участок с многолетней распашкой характеризовался меньшим содержанием агрономически ценных фракций в слое 0-20 см - отклонение составило $7 \%$ относительно целины, расположенной в 200 метров. Для почв с высокой степенью оструктуренности это не столь значимая разница, однако тенденция постепенного ухудшения их агрофизических свойств присутствует. Коэффициент структурности также подтверждает негативное влияние многолетней распашки на физические свойства пахотных темно-серых лесных почв. Отклонение составило $27 \%$ относительно целины

Об ухудшении структурного состояния свидетельствует формирование глыбистых агрегатов (>10 мм), содержание которых в пахотном слое возросло в 2,5-3,0 раза относительно целины. Необходимо отметить, что доля фрракции 
7,0-10 мм в 2 раза больше содержания агрегатов размером 3-5 и 2-3 мм. Это обусловлено сильным варьированием влажности на протяжении вегетационного периода. Содержание мелкозема в пахотном слое не имело серьезных отклонений относительно целины, что может быть объяснено его быстрым оструктуриванием мелкой фракции за счет достаточного количества гумусовых веществ.

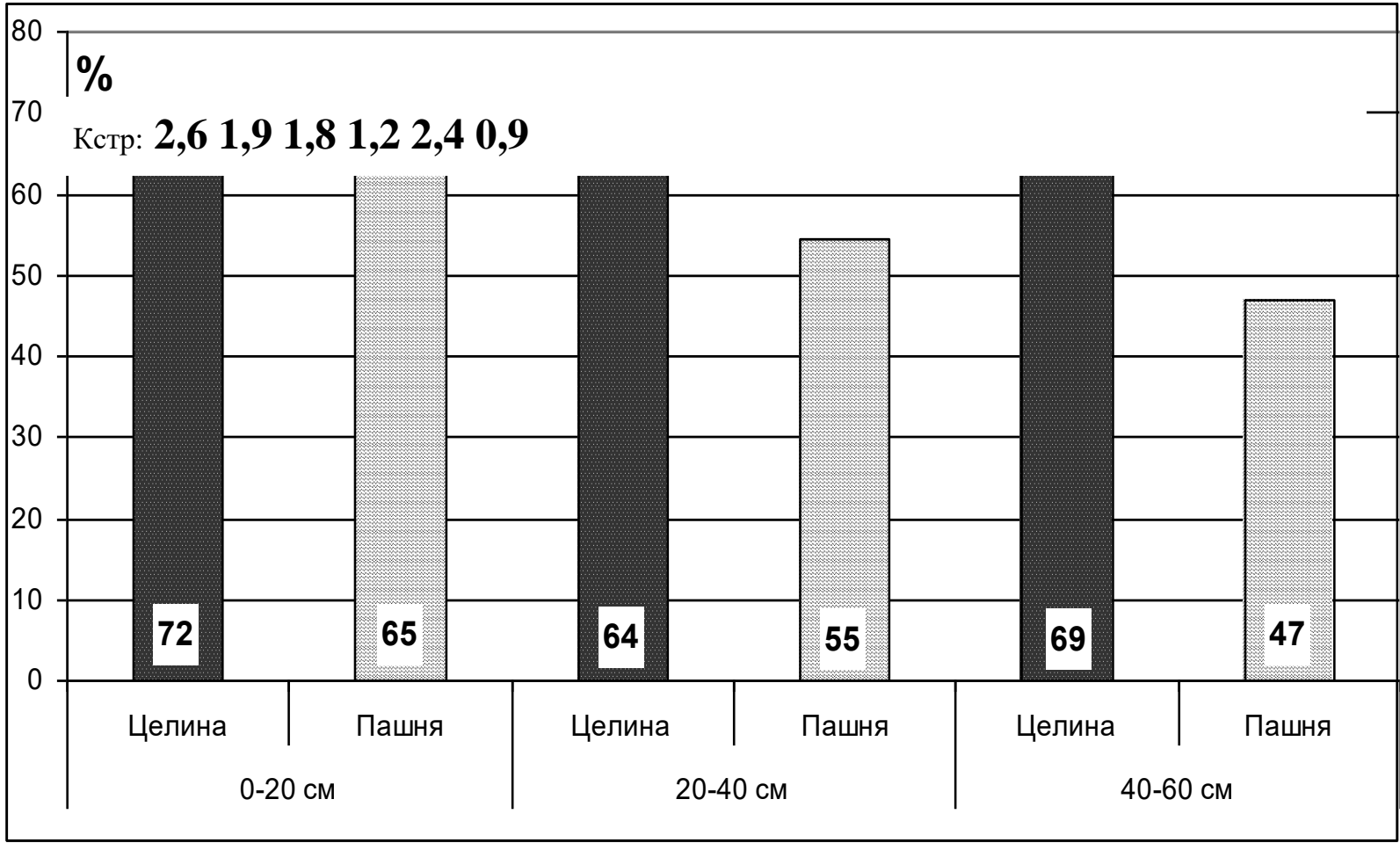

Содержание агрономически цеенных фракций (\%) и коэффициент структурности (Кстр.) темно-серой лесной почвы (сухое просеивание), \%

Влияние ежегодных механических обработок на почву было отмечено и глубже $20 \mathrm{~cm}$. В подпахотном слое (20-40 см) содержание агрономически ценных агрегатов варьировало от 49 до $60 \%$ с минимальным значением в слое 30-40 см. Установлено, что глубже 20 см в пахотной темносерой лесной почве происходит активное формирование глыбистой структуры. Этому способствует сочетание таких факторов, как частое иссушение почвы, перемещение илистых частиц и давление, оказываемое сельскохозяйственной техникой. При сухом просеивании доля мелкозема в слое 20-40 была минимальна. Коэфффициент структурности (Кстр.) был на 33 \% ниже значений целины и составил 1,2 ед., что соответствовало хорошему агрегатному состоянию.

В слое 40-60 см физическое воздействие от давления сельскохозяйственной техники еще присутствует, но в меньшей степени. Поэтому глыбистых агрегатов содержится относительно меньше целины, но достоверно возросла доля пылеватых фрракций, составляющих основу мелкозема. Это привело к снижению Кстр. до 0,9 ед., что почти в 3 раза ниже значений целины.

Мокрый рассев почвы дает качественную характеристику структурно-агрегатного состава почв, которая может существенно отличаться от соответствующих значений при сухом просеивании. Исследования показали, что содержание мелкозема в слое 0-20 см целинной почвы составляет $31 \%$, а водопрочность соответственно равна $69 \%$ (табл.). Это соответствует хорошей водоустойчивости почвенных агрегатов. Отношение содержания мелкозема при мокром и сухом просеивании равно 1,5 ед., что характерно для почв черноземного ряда $[10,11]$.

Многолетнее использование в пашне темносерых лесных почв привело к потере водоустойчивости пахотного горизонта. Коэфффициент 
водопрочности составил $57 \%$, а отношение мелкозема при сухом и мокром просеивании возросло до 2,3 ед. Это указывает на слабую устойчивость темно-серых лесных почв к антропогенному воздействию. Несмотря на то что пахотный горизонт соответствует категории хорошей водоустойчивости, в условиях Северного Зауралья это может привести к нарушению движения воды и воздуха в почве [12, 13]. В подпахотном слое 20-40 см и глубже коэффрициент водопрочности пахотной темно-серой лесной почвы не отличался от значений целины. Отклонения были в пределах ошибки опыта.

Важным показателем агрофизического состояния почв является средневзвешенный диаметр (СВД) агрегатов при сухом и мокром просеивании. Оптимальным размером структурных отдельностей считают 3-5 мм. Более крупные отдельности препятствуют тесному контакту корней с почвой, усиливают физическое испарение воды из корнеобитаемой зоны. Агрегаты менее 3 мм формируют плотные слои почвы, через которые воздух с большим трудом проходит вглубь. В условиях периодически промывного типа водного режима это приводит к ухудшению аэрации.

Как показали наши расчеты, СВД агрегатов в слое 0-20 см целинной темно-серой лесной почвы близок к оптимуму и составляет 2,8 мм, а водопрочных - 2,1 мм. Структурообразование темно-серых лесных почв Северного Зауралья существенно ниже, чем в черноземных почвах, где этот показатель варьирует от 3,5 до 5,0 мм $[14,15]$.

\section{Показатели структурно-агрегатного состава темно-серой лесной почвы}

\begin{tabular}{|c|c|c|c|c|c|}
\hline \multirow{2}{*}{$\begin{array}{c}\text { Слой почвы, } \\
\text { см }\end{array}$} & \multirow{2}{*}{ Угодье } & \multicolumn{2}{c|}{$\begin{array}{c}\text { Содержание мелкозема при } \\
\text { просеивании }\end{array}$} & \multicolumn{2}{c|}{$\begin{array}{c}\text { Средневзвешенный диаметр } \\
\text { (СВД) агрегатов при просеивании }\end{array}$} \\
\cline { 3 - 6 } & & Сухое & Мокрое & Сухое & Мокрое \\
\hline \multirow{2}{*}{$0-20$} & Целина & 21 & 31 & 2,8 & 2,1 \\
\cline { 2 - 6 } & Пашня & 19 & 43 & 3,8 & 1,4 \\
\hline \multirow{2}{*}{$20-40$} & & 2 & 2 & 0,3 & 0,4 \\
\hline \multirow{2}{*}{205} & Целина & 24 & 42 & 3,3 & 2,0 \\
\cline { 2 - 6 } & Пашня & 11 & 40 & 5,4 & 1,3 \\
\hline $\mathrm{HCP}_{05}$ & & 2 & 2 & 0,4 & 0,2 \\
\hline \multirow{2}{*}{$40-60$} & Целина & 13 & 37 & 4,1 & 2,1 \\
\cline { 2 - 6 } & Пашня & 10 & 35 & 6,2 & 1,4 \\
\hline $\mathrm{HCP}_{05}$ & & 1 & 3 & 0,4 & 0,2 \\
\hline
\end{tabular}

Многолетняя распашка привела к формированию характерного для антропогеннопреобразованных почв структурно-агрегатного состава. Средневзвешенный диаметр агрегатов пахотного слоя составил 3,8 мм, что оказалось в диапазоне оптимума и на $35 \%$ выше значений целины. Однако после мокрого рассева СВД уменьшился более чем в 2 раза. Это свидетельствует о том, что темно-серые лесные почвы обладают хорошим потенциалом для формирования благоприятной для растений структуры, но для сохранения ее водоустойчивости необходимы мероприятия по улучшению качественного гумусового состояния. На фоне многолетней вспашки СВД агрегатов достоверно увеличивался, достигая 6,2 мм в слое 40-60 см. Средний размер водоустойчивых агрегатов по всему профилю пахотной темно-серой лесной почвы был равен 1,3-1,4 мм, что может привести к снижению плодородия пахотных почв Северного Зауралья.

\section{Выводы}

1. Целинные темно-серые лесные почвы лесостепной зоны Зауралья характеризуются отличным структурно-агрегатным состоянием. Содержание агрономически ценных фрракций достигает 70 \% при коэфффициенте структурности 2,6 ед. Водоустойчивость почвенных агрегатов варьирует в почвенном профиле 0-60 см от 54 до 63 \%; средневзвешенный диаметр водоустойчивых агрегатов в среднем по профилю составляет 2,0-2,1 мм. 
2. Многолетнее использование темно-серых лесных почв в пашне привело к незначительному ухудшению их структурного состояния за счет формирования глыбистой структуры в слое 0-60 см. Содержание агрономически ценных агрегатов в пахотном слое уменьшилось до $65 \%$, Кстр. - до 1,9 ед., а в слое 40-60 см - до 0,9 ед.

3. Водопрочность структуры пахотного слоя темно-серых лесных почв незначительно варьирует по слою 0-30 см от 57 до $60 \%$, что соответствует хорошей водоустойчивости. Средневзвешенный диаметр структурных агрегатов при мокром просеивании составляет 1,3-1,4 мм, что существенно ниже показателей оптимума (35 мм). В более глубоких слоях пахотной темносерой лесной почвы водопрочность агрегатов не отличалась от значений целины.

4. Для предотвращения ухудшения агрофизических свойств темно-серых лесных почв интенсивность их использования в пашне должна быть уменьшена путем сокращения механических обработок и введения в севооборот многолетних трав, обеспечивающих формирование агрономически ценной структуры.

\section{Литература}

1. Каретин Л.Н. Почвы Тюменской области. Новосибирск: Наука, 1990. - 285 с.

2. Иваненко А.С. 4 века тюменского поля. Свердловск: Сред.-Урал. кн. изд-во, 1990. $205 \mathrm{c}$.

3. Сорокина О.А. Агрогенная трансформация серых лесных почв. - Красноярск: Изд-во КрасГАУ, 2008. - 176 c.

4. Еремин Д.И., Груздева Н.А. Изменение гумусового состояния серых лесных почв восточной окраины Зауральского Плато под действием длительной распашки // Почвоведение. - 2018. - № 7. - С. 826-835. DOI: 10.1134/S0032180X18070110.

5. Sorokina O.A. Diagnostic parameters of soil formation in grey forest soils of abandoned fields overgrowing with pine forests in the middle reaches of the Angara river // Eurasian Soil Science. - 2010. - T.43. - № 8. - P. 867-875. DOI: $10.1134 / S 1064229310080041$.

6. Еремина Д.В. Математическая модель минерального питания яровой пшеницы по результатам многолетних исследований государственного аграрного университета Северного Зауралья // Вестник КрасГАУ. 2017. - № 1 (124). - C. 14-19.

7. Eremina $D$. IT-technologies in soil informatics and Russian agribusiness //B сборнике: MATEC Web of Conferences Ser. «International Science Conference SPbWOSCE-2017 "Business Technologies for Sustainable Urban Development». - 2018. - P. 04016. DOI: 10.1051/matecconf/201817004016.

8. Lyubimova A., Eremin D. 2018 Laboratory varietal control as a guarantee of successful work of gribusiness in Russia MATEC Web of $\begin{array}{llll}\text { Conferences } & 170 & 04015 . & \text { DOI: }\end{array}$ 10.1051/matecconf/201817004015.

9. Казак А.А., Логинов Ю.П. Ценные сорта яровой мягкой пшеницы сибирской селекции - надежный резерв для создания новых сортов в регионе // Вестник Бурятской государственной сельскохозяйственной академии им. В.Р. Филиппова. - 2018. № 4 (53). - С. 8-17.

10. Еремин Д.И. Особенности динамики структурно-агрегатного состояния и плотности сложения выщелоченного чернозема в северной лесостепи Тюменской области // Аграрный вестник Урала. - 2008. - № 3. C. 62-64.

11. Структурно-агрегатное состояние чернозема обыкновенного в агроценозах Средней Сибири / Н.Л. Кураченко, С.Н. Солодченко, Н.В. Романов [и др.] // Аграрная наука. 2008. - № 10. - C. 15-16.

12. Ренев Е.П., Еремин Д.И. Водопроницаемость пахотного чернозема выщелоченного в лесостепной зоне Зауралья // Достижения науки и техники АПК. - 2017. - Т 31. № 10. - С. 18-21.

13. Еремин Д.И., Отекина Н.Е. Влияние длительного сельскохозяйственного использования на структурно-агрегатный состав и водопроницаемость выщелоченного чернозёма Северного Зауралья // Вестник Тюменской государственной сельскохозяйственной академии. - 2010. - № 1. - С. 44-49.

14. Еремин Д.И. Агрогенная трансформация чернозема выщелоченного Северного Зауралья: автореф. дис. ... д-ра биол. наук. Тюмень, 2012. - 34 с. 
15. Влияние орошения на физические и воднофизические свойства агропочв / Е.Г. Ещенко, С.И. Ещенко, В.Л. Татаринцев [и др.] // Вестник Алтайского государственного аграрного университета. - 2018. - № 7 (165). - C. 50-58.

\section{Literatura}

1. Karetin L.N. Pochvy Tjumenskoj oblasti. - Novosibirsk: Nauka, 1990. - $285 \mathrm{~s}$.

2. Ivanenko A.S. 4 veka tjumenskogo polja. Sverdlovsk: Sred.-Ural. kn. izd-vo, 1990. $205 \mathrm{~s}$.

3. Sorokina O.A. Agrogennaja transformacija seryh lesnyh pochv. - Krasnojarsk: Izd-vo KrasGAU, 2008. - $176 \mathrm{~s}$.

4. Eremin D.I., Gruzdeva N.A. Izmenenie gumusovogo sostojanija seryh lesnyh pochv vostochnoj okrainy Zaural'skogo Plato pod dejstviem dlitel'noj raspashki II Pochvovedenie. - 2018. - № 7. - S. 826-835. DOI: $10.1134 / \mathrm{S} 0032180 \times 18070110$.

5. Sorokina O.A. Diagnostic parameters of soil formation in grey forest soils of abandoned fields overgrowing with pine forests in the middle reaches of the Angara river // Eurasian Soil Science. - 2010. - T.43. - № 8. - P. 867-875. DOI: $10.1134 / \mathrm{S} 1064229310080041$.

6. Eremina D.V. Matematicheskaja model' mineral'nogo pitanija jarovoj pshenicy po rezul'tatam mnogoletnih issledovanij gosudarstvennogo agrarnogo universiteta Severnogo Zaural'ja // Vestnik KrasGAU. 2017. - № 1 (124). - S. 14-19.

7. Eremina D. IT-technologies in soil informatics and Russian agribusiness /N sbornike: MATEC Web of Conferences Ser. «International Science Conference SPbWOSCE-2017 "Business Technologies for Sustainable Urban Development». - 2018. - P. 04016. DOI: 10.1051/matecconf/201817004016.
8. Lyubimova A., Eremin D. 2018 Laboratory varietal control as a guarantee of successful work of gribusiness in Russia MATEC Web of Conferences $\quad 170 \quad 04015 . \quad$ DOI: 10.1051/matecconf/201817004015.

9. Kazak A.A., Loginov Ju.P. Cennye sorta jarovoj mjagkoj pshenicy sibirskoj selekcii nadyozhnyj rezerv dlja sozdanija novyh sortov v regione /I Vestnik Burjatskoj gosudarstvennoj sel'skohozjajstvennoj akademii im. V.R. Filippova. - 2018. - № 4 (53). - S. 8-17.

10. Eremin D.I. Osobennosti dinamiki strukturnoagregatnogo sostojanija i plotnosti slozhenija vyshhelochennogo chernozema $\mathrm{v}$ severnoj lesostepi Tjumenskoj oblasti // Agrarnyj vestnik Urala. - 2008. - № 3. - S. 62-64.

11. Strukturno-agregatnoe sostojanie chernozema obyknovennogo v agrocenozah Srednej Sibiri / N.L. Kurachenko, S.N. Solodchenko, N.V. Romanov [i dr.] // Agrarnaja nauka. - 2008. № 10. - S. 15-16.

12. Renev E.P., Eremin D.I. Vodopronicaemost' pahotnogo chernozema vyshhelochennogo $\mathrm{v}$ lesostepnoj zone Zaural'ja // Dostizhenija nauki i tehniki APK. - 2017. - T 31. - № 10. S. 18-21.

13. Eremin D.I., Otekina N.E. Vlijanie dlitel'nogo sel'skohozjajstvennogo ispol'zovanija na strukturno-agregatnyj sostav i vodopronicaemost' vyshhelochennogo chernozjoma Severnogo Zaural'ja // Vestnik Tjumenskoj gosudarstvennoj sel'skohozjajstvennoj akademii. - 2010. - № 1. - S. 44-49.

14. Eremin D.I. Agrogennaja transformacija chernozema vyshhelochennogo Severnogo Zaural'ja: avtoref. dis. ... d-ra biol. nauk. Tjumen', 2012. - $34 \mathrm{~s}$.

15. Vlijanie oroshenija na fizicheskie i vodnofizicheskie svojstva agropochv / E.G. Eshhenko, S.I. Eshhenko, V.L. Tatarincev [i dr.] // Vestnik Altajskogo gosudarstvennogo agrarnogo universiteta. - 2018. - № 7 (165). S. 50-58. 